\title{
Penentuan Kadar Boraks pada Karak Berkode Registrasi dengan Metode Spektrofotometri UV-Vis
}

\author{
The Determination of Borax Levels in Registered Karak (Javanese Thin Fried Rice Cracker) \\ using UV-Vis Spectrophotometric Method
}

\author{
Diah Anggraheni Setianingsih ${ }^{1}$ dan Dian Kresnadipayana ${ }^{2 *}$ \\ ${ }^{1}$ Program Studi D-III Analis Kesehatan Fakultas Ilmu Kesehatan, Universitas Setia Budi Surakarta \\ ${ }^{2}$ Program Studi D-IV Analis Kesehatan Fakultas Ilmu Kesehatan, Universitas Setia Budi Surakarta \\ *Corresponding author: dian.kresnadipayana@gmail.com \& diankresna@setiabudi.ac.id
}

\begin{abstract}
ABSTRAK
Boraks sejak lama digunakan masyarakat Indonesia untuk pembuatan karak. Karak yang beredar di masyarakat terdapat dalam dua bentuk yakni karak berkode registrasi berupa nomor P-IRT (Produk Industri Rumah Tangga) dan tanpa kode registrasi. Karak berkode registrasi diasumsikan bebas dari penggunaan boraks karena telah melalui pengujian oleh dinas kesehatan kabupaten atau kota. Penelitian ini bertujuan untuk mengetahui kadar boraks pada karak berkode registrasi dengan metode spektrofotometri UV-Vis.

Ekstraksi boraks dari sampel karak berkode registrasi dengan cara disentrifuse dengan kecepatan 3000 rpm selama 2 menit kemudian diambil bagian supernatannya. Identifikasi boraks dalam supernatant tersebut dilakukan secara kualitatif dengan menggunakan pereaksi kurkumin dan secara kuantitatifmenggunakan spektrofotometri UV-Vis.

Hasil penelitian menunjukkan bahwa kadar boraks pada sampel karak berkode registrasi A, B, dan C berturut-turut adalah 1,988 mg/gram, 1,975 mg/gram dan 1,438 mg/gram. Menurut PERMENKES RI Nomor 033 tahun 2012 tentang bahan tambahan pangan, bahwa boraks digolongkan dalam bahan tambahan yang dilarang digunakan dalam makanan.
\end{abstract}

Kata kunci: karak berkode registrasi, boraks, spektrofotometri UV-Vis

\section{ABSTRACT}

Borax has been long used by Indonesian people to make karak or Javanese thin fried rice cracker. There are two types of karak widely available in the societies, namelyP-IRT (Home Industry Product) registered karak and unregistered karak. Registered karak is assumed to be free from borax since it has been tested by health agency of regency or city. This study aims at investigating the borax levels in registeredkarak using UV-VIS spectrophotometric method.

Borax extracts from the samples of registered karak were obtained using centrifuge at 3,000 rpm within 2 minutes and the supernatants were taken. Identification of borax in supernatants was carried out qualitatively using curcumin reagent and quantitatively using UV-VIS spectrophotometry.

The research results show that the borax levels in the samples of registered karak $A, B$, and $C$ are $1.988 \mathrm{mg} / \mathrm{gram}$, $1.975 \mathrm{mg} / \mathrm{gram}$ and $1.438 \mathrm{mg} / \mathrm{gram}$, respectively. According to the Regulation of the Minister of Health of the Republic of Indonesia Number 33 Year 2012 on food additives, borax is categorized as banned food additive.

Keywords: registered karak, borax, UV-VIS spectrophotometry.

\section{PENDAHULUAN}

Karak atau yang biasa disebut dengan kerupuk nasi, gendar maupun kerupuk puli merupakan kerupuk yang sangat familiar dan digemari oleh sebagian masyarakat Indonesia khususnya masyarakat Jawa Tengah dan Jawa Timur (Lathifah, 2015). Boraks sejak lama digunakan oleh masyarakat Indonesia untuk pembuatan karak. Boraks secara lokal dikenal sebagai air bleng, garam bleng atau pijer (Sugiyono, dkk., 2009). Menurut Setyowati (2010), dalam proses pembuatan karak, bleng digunakan untuk memperbaiki tekstur (kenyal) adonan, sehingga mudah pengirisannya, awet, setelah digoreng mengembang, empuk, teksturnya bagus dan renyah.

Karak yang beredar di masyarakat terdapat dalam dua jenis yakni karak berkode registrasi 
dan tanpa kode registrasi. Karak tanpa kode registrasi diasumsikan mengandung boraks karena tidak melalui serangkaian pengujian sedangkan karak berkode registrasi diasumsikan bebas dari adanya cemaran boraks karena telah melalui serangkaian pengujian yang dilakukan oleh Dinas Kesehatan kabupaten atau kota. Karak merupakan produk industri berskala rumah tangga, sehingga kode registrasi yang diperoleh dari Dinas Kesehatan kabupaten atau kota berupa nomor P-IRT (Produk Industri Rumah Tangga).

Berdasarkan berita online yang dimuat di Harian Umum Independen Singgalang tanggal 29 Januari 2016 mengatakan bahwa BPOM Padang menemukan kerupuk nasi mengandung boraks di Pasar Banda Buek Padang. Kerupuk nasi mengandung boraks temuan BPOM Padang berasal dari Pulau Jawa (Singgalang, 2016).

Menurut PERMENKES RI Nomor 033 Tahun 2012 tentang bahan tambahan pangan, bahwa boraks digolongkan dalam bahan tambahan yang dilarang digunakan dalam makanan. Boraks sangat berbahaya bagi kesehatan apabila terdapat dalam makanan. Boraks pada pemakaian sedikit dan lama akan terjadi akumulasi (penumpukan) pada otak, hati, lemak dan ginjal (Ulfa, 2015).

Metode analisis boraks dapat dilakukan dengan beberapa cara yakni secara kualitatif dan kuantitatif. Salah satu metode analisis secara kuantitatif yakni dengan menggunakan metode spektrofotometri UV-Vis. Metode ini memiliki sensitivitas dan spesifikasi yang tinggi dan dapat digunakan untuk penetapan sampel dengan kadar yang sangat kecil (Rusli, 2009).

Penelitian ini bertujuan untuk mengetahui apakah sampel karak berkode registrasi mengandung boraks dan berapa kadarnya. Manfaat yang diperoleh dari penelitian ini yakni menambah wawasan dan pengalaman studi penelitian pada kimia pangan khususnya dalam mengidentifikasi boraks secara kualitatif dan kuantitatif, sebagai informasi bagi masyarakat dalam memilih makanan olahan yang aman dikonsumsi dan sebagai upaya pemantauan penggunaan BTM yang dilarang serta sebagai masukan bagi instansi terkait agar lebih memperhatikan penggunaan boraks khususnya pada karak.

\section{METODE PENELITIAN}

\section{Alat dan Bahan}

Instrumen spektrofotometer UV-Vis, waterbath, oven, sentrifuge, blender, timbangan elektrik, kertas saring dan alat gelas yang umum terdapat di laboratorium. Bahan berupa Kurkumin, etanol absolute, serbuk boraks, asam asetat pekat, $\mathrm{NaOH} 10 \%$, asam sulfat pekat, kertas saring, akuades, sampel karak berkode registrasi yang dijual di Kota Surakarta Provinsi Jawa Tengah. Sampel yang diambil untuk penelitian sebanyak 3 sampel dengan kode registrasi yang berbeda-beda.

\section{Penentuan Kadar Boraks pada Karak Berkode Registrasi dengan Metode Spektrofotometri UV-Vis}

a. Ekstraksi Sampel Karak

Sebanyak 5 gram sampel karak ditambah dengan $20 \mathrm{~mL}$ akuades lalu diblender sampai halus. Larutan tersebut dimasukkan ke dalam tabung sentrifugasi. Alat dihidupkan selama 2 menit dengan kecepatan 3000 rpm. Bagian supernatannya diambil dengan cara disaring dengan kertas saring dan kemudian supernatant diuji secara kualitatif dan kuantitatif (Kresnadipayana dan Lestari, 2017).

\section{b. Analisis Sampel}

1) Uji Kualitatif

Metoda analisa boraks atau asam borat secara kualitatif dapat dilakukan dengan cara uji menggunakan kurkumin cair. Supernatant dipipet sebanyak $1 \mathrm{~mL}$ dari masing-masing sampel kemudian dimasukkan ke dalam cawan porselin dan ditambah $1 \mathrm{~mL}$ larutan asam sulfat 
pekat. Cawan tersebut dipanaskan di atas penangas air sampai kering, kemudian pemanasan dilanjutkan dengan oven pada suhu $100^{\circ} \pm 5^{\circ} \mathrm{C}$ selama 5 menit, dan didinginkan (Kresnadipayana dan Lestari, 2017).

Larutan ditambah $3 \mathrm{~mL}$ larutan kurkumin $0,125 \%$ kemudian dipanaskan sambil diaduk selama \pm 3 menit diamati terjadinya perubahan warna residu yang berwarna merah cherry.

\section{2) Uji Kuantitatif}

a) Penentuan Panjang Gelombang Maksimum Larutan induk boraks dibuat dengan menimbang $50 \mathrm{mg}$ serbuk boraks dalam $100 \mathrm{~mL}$ akuades sehingga konsentrasi larutan menjadi 500 ppm. Larutan induk boraks 500 ppm tersebut diencerkan menjadi konsentrasi 10 ppm; 0,2 ppm; 0,4 ppm; 0,6 ppm; 0,8 ppm dan 1,0 ppm dengan mengambil sebanyak $10 \mathrm{~mL}$ untuk $10 \mathrm{ppm}, 5 \mathrm{~mL}$ untuk $0,2 \mathrm{ppm} ; 10 \mathrm{~mL}$ untuk 0,4 ppm; $15 \mathrm{~mL}$ untuk 0,6 ppm; $20 \mathrm{~mL}$ untuk 0,8 ppm dan $25 \mathrm{~mL}$ untuk 1,0 ppm yang kemudian ditambah $25 \mathrm{~mL}$ akuades ke dalam labu ukur ukuran $25 \mathrm{~mL}$ sedangkan konsentrasi 10 ppm ditambahkan $50 \mathrm{~mL}$ aquadest ke dalam labu ukur $50 \mathrm{~mL}$.

Selanjutnya sebanyak $0,5 \mathrm{~mL}$ larutan boraks dari masing-masing konsentrasi yang sudah dibuat dimasukkan ke dalam cawan porselin, ditambah 0,5 mL larutan $\mathrm{NaOH} 10 \%$ kemudian dipanaskan di atas penangas air sampai larutan kering. Pemanasan dilanjutkan dengan oven pada suhu $100^{\circ} \pm 5^{\circ} \mathrm{C}$ selama 5 menit, dan didinginkan.

Larutan ditambah 1,5 mL larutan kurkumin $0,125 \%$ dipanaskan sambil diaduk selama \pm 3 menit dan didinginkan lagi. Setelah dingin larutan ditambah 1,5 mL larutan asam sulfat dan asam asetat (1:1), sambil diaduk sampai tidak ada warna kuning baik pada cawan maupun pada pengaduk, didiamkan selama \pm 8 menit. Larutan ditambah sedikit etanol kemudian disaring dengan kertas saring lalu dimasukkan ke dalam labu ukur $25 \mathrm{~mL}$, dan labu ukur $50 \mathrm{~mL}$ untuk konsentrasi 10 ppm kemudian diencerkan dengan etanol sampai garis tanda (Kresnadipayana dan Lestari, 2017).

Larutan standar boraks 10 ppm dari boraks murni, digunakan untuk menentukan panjang gelombang maksimum. Hasil saringan larutan yang sudah dipreparasi tersebut dikumpulkan dan diamati serapannya pada panjang gelombang antara 500 sampai $600 \mathrm{~nm}$ pada alat spektrofotometer UV-Vis.

Uji validasi metode analisis untuk pembuatan kurva kalibrasi digunakan larutan standar boraks pada 5 konsentrasi yaitu 0,2 ppm; 0,4 ppm; 0,6 ppm; 0,8 ppm, dan 1,0 ppm. Seri larutan standar boraks diukur absorbansinya pada panjang gelombang maksimum yang telah diperoleh.

\section{b) Penentuan Kadar Sampel Karak}

Sebanyak 5 gram sampel karak ditambah dengan $20 \mathrm{~mL}$ akuades lalu diblender sampai halus, kemudian dimasukkan ke dalam tabung sentrifugasi, alat dihidupkan selama 2 menit dengan kecepatan 3000 rpm sampai terbentuk dua lapisan. Lapisan atas (supernatant) diambil dengan cara disaring dengan kertas saring (Kresnadipayana dan Lestari, 2017).

Supernatant dipipet sebanyak $0,5 \mathrm{~mL}$ dari masing-masing sampel kemudian dimasukkan ke dalam cawan porselin dan ditambah $0,5 \mathrm{~mL}$ larutan $\mathrm{NaOH}$ 10\%. Cawan tersbut dipanaskan di atas penangas air sampai kering, kemudian pemanasan dilanjutkan dengan oven pada suhu $100^{\circ} \pm 5^{\circ} \mathrm{C}$ selama 5 menit, dan didinginkan (Kresnadipayana dan Lestari, 2017).

Larutan ditambah 1,5 mL larutan kurkumin $0,125 \%$ kemudian dipanaskan sambil diaduk selama \pm 3 menit, lalu didinginkan kembali. Setelah dingin larutan ditambah 1,5 $\mathrm{mL}$ larutan asam sulfat pekat dan asam asetat (1:1), sambil diaduk sampai tidak ada warna kuning baik pada cawan maupun pada pengaduk lalu didiamkan selama \pm 7 menit (Kresnadipayana dan Lestari, 2017). 
Campuran ditambah sedikit etanol kemudian disaring dengan kertas saring kemudian dimasukkan ke dalam labu ukur 25 $\mathrm{mL}$, diencerkan dengan etanol sampai tanda batas. Hasil saringan dikumpulkan untuk diamati serapannya pada panjang gelombang maksimum yang telah diperoleh (Kresnadipayana dan Lestari, 2017).

\section{HASIL DAN PEMBAHASAN}

\section{Preparasi Sampel Karak}

Ekstraksi sampel dilakukan dengan menggunakan pelarut air. Diharapkan boraks akan terlarut dalam pelarut air sesuai dengan kalarutan boraks yakni larut dalam 20 bagian air. Metode sentrifugasi dipilih karena mudah, efektif serta menggunakan alat yang lebih sederhana. Sentrifugasi dilakukan untuk memisahkan antara supernatant dan sedimen dari hasil ekstraksi sampel karak. Supernatant yang diperoleh diduga mengandung boraks sehingga dapat diidentifikasi.

Identifikasi boraks dalam supernatant tersebut dilakukan secara kualitatif dengan menggunakan pereaksi kurkumin dan secara kuantitatif menggunakan spektrofotometri UVVis.

\section{Uji Kualitatif Boraks pada Karak}

Adanya boraks dalam suatu makanan apabila diidentifikasi menggunakan kurkumin cair diamati dari perubahan warna residu menjadi merah cherry sedangkan apabila sampel tidak mengandung boraks maka warna larutan tetap berwarna kuning (Tabel 1).
Pada suasana asam kuat, boraks terurai dari ikatan-ikatannya menjadi asam borat dan diikat oleh kurkumin membentuk kompleks warna rosa yang sering disebut kelat rosasianin atau senyawa Boron Cyano Kurkumin Kompleks yaitu suatu zat yang berwarna merah. Dari hasil uji menunjukkan bahwa sampel A, B dan C teridentifikasi adanya boraks.

\section{Boraks pada Sampel dengan Metode Spektrofotometri UV-Vis}

a. Penentuan Panjang Gelombang Maksimal

Nilai serapan yang diamati pada panjang gelombang antara 500 sampai $600 \mathrm{~nm}$ pada spektrofotometer UV-Vis. Pada kurva panjang gelombang pada Gambar 1 menunjukkan bahwa terdapat dua panjang gelombang yakni 549,00 dan 519,00 nm. Panjang gelombang $549,00 \mathrm{~nm}$ merupakan panjang gelombang maksimal. Hasil pengukuran panjang gelombang serapan maksimum boraks tersebut dipilih berdasarkan nilai serapan tertinggi.

Hasil penentuan panjang gelombang maksimum pada penelitian ini sebesar 549,00 $\mathrm{nm}$ tidak berbeda jauh dengan panjang gelombang maksimal peneliti yang lain yakni 545,9 nm (Rusli, 2009); 546 nm (Rahman dkk, 2016); 547nm (Sudjarwo dkk, 2014); 547 nm (Dewi, 2011); 549,05 nm (Azas, 2013); $550 \mathrm{~nm}$ (Marczenko, Z dan M Balcerzak, 2000 dalam Sudjarwo dkk, 2014).

\section{b. Penentuan Kurva Standar}

Penetapan kurva baku dilakukan dengan cara membuat seri larutan baku yaitu 0,2 ppm;

Tabel 1. Hasil Uji Kualitatif terhadap Boraks dengan Pereaksi Kurkumin

\begin{tabular}{|c|c|c|}
\hline Sampel Karak & Warna & Hasil (+/-) \\
\hline A & Merah & + \\
\hline B & Merah & + \\
\hline C & Merah & + \\
\hline
\end{tabular}

Catatan: tanda $(+)=$ positif mengandung boraks tanda $(-)=$ tidak mengandung boraks 


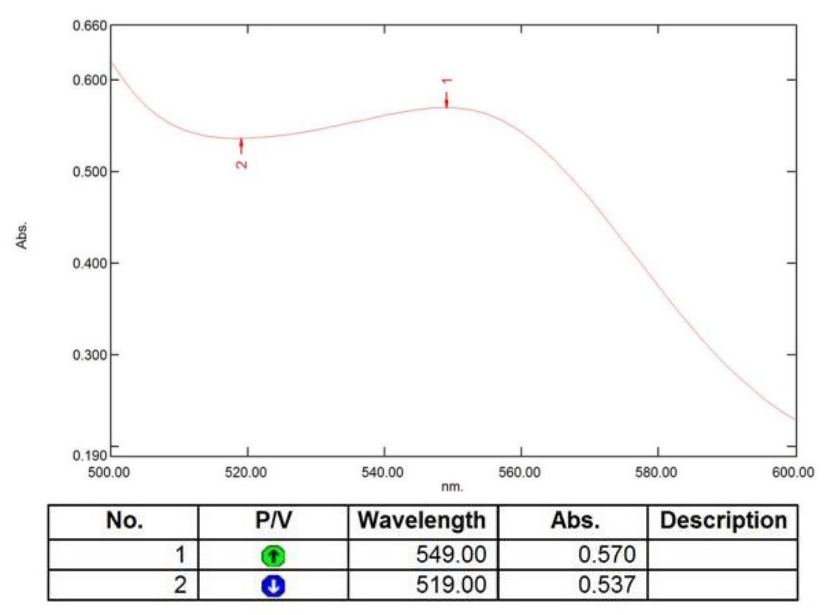

Gambar 1. Kurva Panjang Gelombang Maksimal Boraks

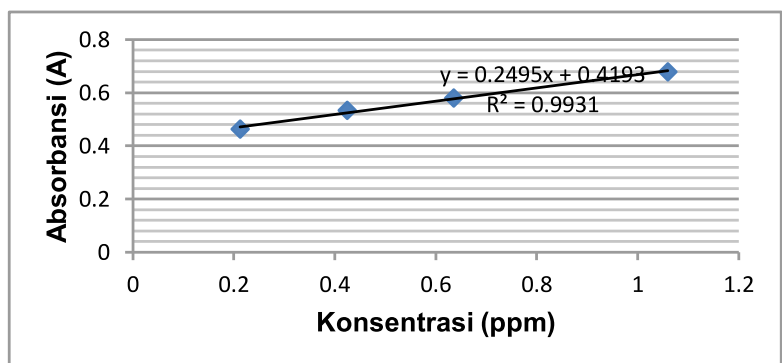

Gambar 2. Kurva Kalibrasi Standar Boraks

Tabel 4. Hasil Kadar Boraks pada Sampel Karak Berkode Registrasi Menggunakan Spektrofotometer UV-Vis

\begin{tabular}{|c|c|c|}
\hline Sampel & Kadar (ppm) & Kadar (mg/gram) \\
\hline A & 9,94 & 1,988 \\
\hline B & 9,87 & 1,975 \\
\hline C & 7,19 & 1,438 \\
\hline
\end{tabular}

0,4 ppm; 0,6 ppm; 0,8 ppm dan 1,0 ppm, kemudian diukur serapannya pada panjang gelombang maksimum 549,00 nm. Kurva kalibrasi standar boraks dapat dilihat pada Gambar 2.

Dari kurva kalibrasi tersebut didapatkan persamaan regresi $\mathrm{y}=0,419+0,249 \mathrm{x}$ dengan koefisien korelasi (r) sebesar 0,993. Menurut Azas (2013) kriteria penerimaan dari koefisien korelasi adalah (r) sebesar $\geq 0,9990$ yang berarti bahwa hasil kurva antara absorban dan konsentrasi tersebut terdapat hubungan yang linier. Kurva baku ini digunakan untuk menghitung kadar zat pada sampel. c. Kadar Boraks pada Sampel A, B dan C

Pada Tabel 4 menunjukkan semua sampel yang dianalisa menggunakan spektrofotometer UV-Vis terbukti mengandung boraks di dalamnya. Berdasarkan PERMENKES Nomor 033 Tahun 2012 bahwa asam borat dan senyawanya merupakan bahan yang dilarang digunakan sebagai bahan tambahan pangan dengan tujuan apapun. Sehingga dalam hal ini, instansi terkait yakni Dinas Kesehatan kabupaten/kota perlu melakukan kontrol terhadap produksi rumah tangga yang telah mendapat nomor registrasi secara berkelanjutan. 
Bila mengkonsumsi makanan yang mengandung boraks tidak langsung berakibat buruk terhadap kesehatan, tetapi senyawa tersebut diserap dalam tubuh secara kumulatif, di samping melalui saluran pencernaan boraks dapat diserap melalui kulit. Konsumsi boraks yang tinggi dalam makanan dan diserap dalam tubuh akan disimpan secara akumulatif dalam hati, otak, dan testis serta akan menyebabkan timbulnya gejala pusing, muntah, mencret dan kram perut. Boraks dapat mempengaruhi alat reproduksi, selain itu juga dapat mempengaruhi metabolisme enzim (BPOM, 2013 dalam Wahyudi, 2016).

\section{KESIMPULAN}

1. Pada sampel karak berkode registrasi A, B dan C secara uji kualitatif teridentifikasi mengandung boraks.

2. Kadar boraks pada sampel karak berkode registrasi yang dianalisis yakni sampel A sebesar 1,988 mg/gram, sampel B sebesar $1,975 \mathrm{mg} /$ gram dan sampel C sebesar 1,438 $\mathrm{mg} / \mathrm{gram}$.

\section{DAFTAR PUSTAKA}

Amelia, R., Endrinaldi dan Z. Edward. 2014. "Identifikasi dan Penentuan Kadar Boraks dalam Lontong yang Dijual di Pasar Raya Padang". Jurnal Kesehatan Andalas, 3 (3): 457-459

Asterina, Elmatris dan Endrinaldi. 2008. "identifikasi dan Penentuan kadar Boraks pada Mie Basah yang Beredar di Beberapa Pasar di Kota Padang”. Majalah Kedokteran Andalas, 32 (2): 174-179

Azas, Q.S. 2013. “Analisis Kadar Boraks pada Kurma yang Beredar Di Pasar Tanah Abang dengan Menggunakan Spetrofotometer UV-Vis". Skripsi. Jakarta: Fakultas Kedokteran dan Ilmu Kesehatan Program Studi Farmasi, UIN Syarif Hidayatullah Jakarta.

DEPKES. 2011. Pedoman Keamanan Pangan di Sekolah Dasar. Direktorat Bina Gizi Ditjen Bina Gizi dan Kesehatan Ibu dan Anak Kementerian Kesehatan Republik Indonesia. (Online), http://gizi.depkes.go.id/download/Pedoman \%20Gizi/Panduan\%20keamanan \%20pangan $\% 2025 \% 20 \mathrm{~J}$ anuari\%202012.pdf, diakses tanggal 2 April 2016.

Dewi, R.W. 2011. "Validasi Metode Spektrofotometri UV-Vis pada Penetapan Kadar Boraks dalam Siomay". Skripsi. Surabaya: Fakultas Farmasi Departemen Kimia Farmasi, Universitas Airlangga.

Habsah. 2012. "Gambaran Pengetahuan Pedagang Mi Basah terhadap Perilaku Penambahan Boraks dan Formalin pada Mi Basah di Kantin-Kantin Universitas X Depok Tahun 2012”. Skripsi. Depok: Fakultas Kesehatan Masyarakat Program Studi Ilmu Gizi Universitas Indonesia.
KeMENDAG. 2013. Analisis Pengawasan Distribusi Bahan Berbahaya. Pusat Kebijakan Perdagangan Dalam Negeri Badan Pengkajian dan Pengembangan Kebijakan Perdagangan Kementerian Perdagangan. (Online),http://www.kemendag.go.id/files/pdf/2015/02/2 7/laporan-analisis-pengawasan-1425036031.pdf, diakses tanggal 2April 2016.

Kresnadipayana, D. dan Lestari, D. 2017. "Penentuan Kadar Boraks dengan Metode Spektrofotometri UV-VIS". Jurnal Wiyata Penelitian Sains dan Kesehatan 4 (1), 23-30.

Lathifah, N.U. 2015. "Pengaruh Penambahan Tepung Tapioka sebagai Pengganti "Bleng" (Boraks) dalam Pembuatan Kerupuk terhadap Tingkat Pengembangan dan Daya Terima Kerupuk Karak. Naskah Publikasi. Surakarta: Program Studi Ilmu Gizi Fakultas Ilmu Kesehatan Universitas Muhammadiyah Surakarta.

Mulja, M dan Suharman. 1995. Analisis Instrumental. Surabaya: Airlangga University Press.

Rahman, K.R.D, Anggi Arumsari dan Diar Herawati. 2016. "Pengembangan Metode Preparasi Sampel Siomay dalam Analisis Natrium Tetraborat". Prosiding Farmasi, 2 (2): 293-299.

Rusli, R. 2009. "Penetapan kadar Boraks pada Mie Basah yang Beredar di Pasar Ciputat dengan Metode Spektrofotometri UV-Vis menggunakan Pereaksi Kurkumin. Skripsi. Jakarta: Program Studi Farmasi Fakultas Kedokteran dan Ilmu Kesehatan Universitas Islam Negeri (UIN) Syarif Hidayatullah Jakarta. 8Saputro, D.H. 2012. "Quality Control (QC) Pengendalian Mutu di Usaha Kecil Menengah "Karak Bapak Budi" Desa Gadingan RT 03/RW 04, Mojolaban Sukoharjo". Tugas Akhir. Surakarta: Program Studi D III Teknologi hasil Pertanian Fakultas Pertanian Universitas Sebelas Maret Surakarta.

Setyowati, A. 2010. "Penambahan Natrium Tripolifosfat dan CMC (Carboxy Methyl Sellulose) pada Pembuatan Karak". Jurnal AgriSains, 1 (1): 40-49

Singgalang. 2016. "Kerupuk Nasi Mengandung Boraks Berasal dari Jawa". (Online),

http://hariansinggalang.co.id/kerupuk-nasi-mengandungborak-berasal-dari-jawa/, diakses tanggal 2 April 2016

Sugiyono, S. Musinah dan Rukanah. 2009. “Analisis Kandungan Boraks sebagai Boron pada Gendar yang Diproduksi oleh Industri Rumah Tangga di Daerah Ambarawa". Jurnal Ilmu Farmasi dan farmasi Klinik, 6 (1): 33-38

Sudjarwo, Poedjiarti S, dan Angerina N. 2014. "Validasi Metode Spektrofotometri-Vis pada Penetapan Kadar Boraks didalam Bakso". Berkala Ilmiah Farmasi, 3 (1): 31-38.

Triatama, J. 2014. "Identifikasi Kandungan Boraks pada Keripik Usus Ayam (Berizin) yang Dijual di Pasar Besar Kota Kualaa Kapuas Kalimantan Tengah". Karya Tulis Ilmiah. Palangkaraya: Fakultas Ilmu Kesehatan Program Studi D III Farmasi Universitas Muhammadiyah Palangkaraya.

Ulfa, A.M. 2015. "Identifikasi Boraks pada Pempek dan Bakso Ikan Secara Reaksi Nyala dan Reaksi Warna”. Jurnal Kesehatan Holistik, 9 (3): 151-157

Wahyudi, A. 2016. "System Pendeteksi Boraks $\left(\mathrm{Na}_{2} \mathrm{~B}_{4} \mathrm{O}_{7} 10\right.$ $\left.\mathrm{H}_{2} \mathrm{O}\right)$ pada bakso Daging sapi Berdasarkan Image dengan Menggunakan Metode Jaringan Saraf Tiruan LVQ (Learning Vector Quantization). Skripsi. Malang: Jurusan Teknik Informatika Fakultas Sains dan Teknologi Universitas Islam Negeri Maulana Malik Ibrahim Malang.

Widayat, D. 2011. "Uji Kandungan Boraks pada Bakso (Studi pada Warung Bakso di Kecamatan Sumbersari kabupaten Jember)". Skripsi. Jember: Bagian Kesehatan Lingkungan dan Kesehatan Keselamatan Kerja Fakultas Kesehatan Masyarakat, Universitas Jember. 